\title{
Caminhos, abelhas e passarinhos: um estudo da mise en scène no documentário Duas aldeias, uma caminhada
}

\author{
José Francisco Serafim ${ }^{1}$ \\ Universidade Federal da Bahia
}

Francisco Gabriel Rêgo ${ }^{2}$ Universidade Federal do Sul da Bahia

Resumo: Este artigo analisa o documentário Duas aldeias, uma caminhada - mokoi tekoá petei jeguatá (2008), realização do coletivo Mbyá-Guarani de Cinema. Busca-se apontar para a importância do território indígena na estruturação do documentário como forma de relacionar os sujeitos envolvidos no processo de registro documental. Buscamos, dessa maneira, abordar as características da mise en scène no documentário, observando o caráter intersubjetivo da cena, presente na relação entre os comentários desenvolvidos pelos sujeitos indígenas nos espaços de registro.

Palavras-chave: documentário; subjetividade; cultura Mbyá-Guarani.

\footnotetext{
${ }^{1}$ Professor Associado da Faculdade de Comunicação (UFBA). Professor e pesquisador do Programa de Pós-graduação em Comunicação e Cultura Contemporâneas (PósCom/UFBA). Pesquisador do Centro de Estudos das Relações Interculturais (CEMRI) da Universidade Aberta de Lisboa. Doutor em cinema documentário (antropológico) pela Universidade Paris X - Nanterre (2000). Coordena o Grupo de Análise de Documentário Nanook, grupo de pesquisa vinculado ao Laboratório de Análise Fílmica (PósCom/UFBA).

${ }^{2}$ Professor Assistente na Universidade Federal do Sul da Bahia (UFSB). Doutorando no Programa de Pós-graduação em Comunicação e Cultura Contemporâneas (PósCom/UFBA). Integra o NANOOK, Grupo de Análise de Documentário, grupo de pesquisa vinculado ao Laboratório de Análise Fílmica (PósCom/UFBA), e o grupo de pesquisa Poéticas Ameríndias (UFSB).
} 


\title{
Paths, bees and birds: a study of mise in scène in the documentary Duas aldeias, uma caminhada
}

\begin{abstract}
This article analyzes the documentary Duas aldeias, uma caminhada mokoi tekoá petei jeguatá (2008), directed by the collective Mbyá Guarani de Cinema. It seeks to point out the importance of the indigenous territory in structuring the documentary as a way of relating the subjects involved in the document registration process. In this way, we seek to approach the characteristics of mise en scène in the documentary, observing the intersubjective character of the scene, present in the relationship between the comments developed by indigenous subjects in the registration spaces.
\end{abstract}

Keywords: documentary; subjectivity; Mbyá-Guarani culture.

\section{Caminos, abejas y pájaros: un estudio de mise en scène en el documental Duas aldeias, uma caminhada}

\begin{abstract}
Resumen: Este artículo analiza el documental Duas aldeias, um viagem - mokoi tekoá petei jeguatá (2008), dirigido por el colectivo Mbyá-Guarani de Cinema. Busca señalar la importancia del territorio indígena en la estructuración del documental como una forma de relacionar a los sujetos involucrados en el proceso de registro documental. De esta manera, buscamos acercarnos a las características de la mise en scène en el documental, observando el carácter intersubjetivo de la escena, presente en la relación entre los comentarios desarrollados por los sujetos indígenas en los espacios de registro.
\end{abstract}

Palabras clave: documental; subjetividad; Cultura Mbyá-Guaraní. 


\section{Discussões iniciais}

$\mathrm{D}$ irigido pelos indígenas Ariel Ortega, Jorge Morinico e Germano Benites3, o documentário Duas aldeias, uma caminhada - mokoi tekoá petei jeguatá (2008), produção do Coletivo Mbyá Guarani de Cinema4, tem como espaço central duas comunidades Mbyá-guarani no Rio Grande do Sul. Por meio de um percurso que envolve o cotidiano e os sujeitos indígenas, o documentário busca desenvolver uma relação entre os espaços indígenas e não indígenas, ao abordar questões importantes concernentes a história oficial e o papel dos guaranis no processo de ocupação territorial do sul do Brasil.

No documentário o limite das reservas indígenas é o mote para a reinterpretação da história oficial, em prol de um reposicionamento dos indígenas como intérpretes de sua cultura, de suas memórias e tradições. Cada vez mais achatados pelo crescimento das cidades, diante da redução das matas e sem terras para o plantio, os Mbyá passam a depender cada vez mais da confecção e venda de artesanatos para serem vendidos aos turistas nas ruínas dos Setes Povos das Missões. É assim que os três jovens realizadores passam a acompanhar o dia a dia das duas aldeias representadas, comunidades perpassadas pelo mesmo passado histórico e pelas problemáticas sociais oriundas do convívio intenso com os não-indígenas.

Nessa análise, propomos uma abordagem das características presentes no processo de realização, de modo a compreender como a utilização dos comentários orais no filme se desenvolve por meio de duas perspectivas: uma primeira, constituída na relação entre os próprios indígenas, e uma segunda, estabelecida na relação entre indígenas e não indígenas. Essas duas possibilidades se relacionam diretamente com os espaços de registro abordados pelo documentário de modo a opor dois territórios importantes para os sujeitos indígenas: as aldeias espaço de enunciação das características culturais, sociais e etnográficas por parte dos indígenas - e a Ruína dos Sete Povos das Missões - território externo onde os indígenas se propõem a um diálogo mediado pela relação com os não indígenas.

Em ambos os espaços, a câmera e seu sujeito tem um papel importante no estabelecimento de diálogos entre os sujeitos envolvidos na cena. Para tanto, a ideia de mise en scéne abordada aqui se relaciona com uma abordagem comum em autores como Jean-Louis Comolli (2008), Claudine de France (1998) e Fernão Pessoa Ramos (2012), ao acentuarem, entre outras características, o caráter intersubjetivo da cena documental, a nos permitir uma observação das características culturais, sociais e etnográfica das comunidades envolvidas.

No primeiro espaço, Aldeia Anhetenguá, um dos jovens segura uma colmeia esvaziada, indicando que as abelhas, sensíveis às transformações do ambiente, haviam escolhido um local melhor para viver (Fig. 1). Em seguida, ainda diante da câmera, o jovem compara os Mbyá às abelhas, que, diante das dificuldades adaptativas do espaço, deslocam-se em busca de novos territórios:

3 membros das duas comunidades Mbya-Guarani: Aldeia Koenju, em Porto Alegre (RS), e Aldeia Anhetenguá, no município de são Miguel das Missões (RS).

4 A filmografia do Coletivo Mbyá-Guarani de Cinema é composta pelos seguintes documentários: Mokoi Tekoá, Petei Jeguatá - Duas aldeias, uma caminhada (2008), Nós e a cidade (2019), Bicicletas de Nahanderú (2011), Desterro Guarani (2011), Mbya mirim (2012), Tava, a casa de pedra (2012) e No caminho com Mário (2014). 
[...] elas não queriam ir embora porque queriam ir. Às vezes os Mbyá se mudam porque tem alguém incomodando. Por isso elas foram tentar viver melhor em outro lugar. Os Mbyá Guarani também são assim. (DUAS ALDEIAS..., 2008, 5’31”)

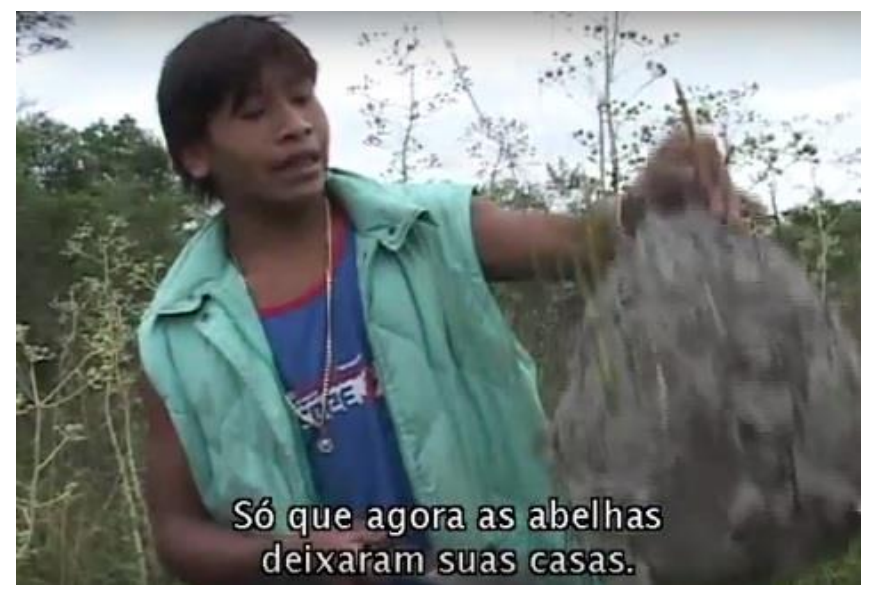

Fig. 1 - Duas aldeias uma caminhada (2008): 5'12"

Nessas palavras, o indígena nos apresenta um aspecto importante da cultura Guarani: a migração territorial. Nessa mesma linha, Maria Inês Ladeira (2007) aponta para a importância da questão territorial para os Mbyá, ressaltando essa problemática como um traço comum a todos os subgrupos Guaranis. Desde o primeiro momento do período colonial, os Guaranis foram assimilados pelo projeto catequético jesuíta, projeto esse que, desde o princípio, buscou assentar os indígenas em torno das chamadas reduções, espaços destinados à aculturação baseado no discurso religioso e que, em meados do sec. XVIII, estiveram associadas a um dos principais conflitos do Brasil Colônia: as Guerras Guaraníticas.

O espaço abordado pelo documentário é um ponto marcante para a sua estrutura. É diante das diferenças e semelhanças entre as duas aldeias envolvidas na representação que a câmera constitui um percurso em direção aos aspectos fundantes da cultura Guarani. Mais do que pertencer a qualquer um dos espaços explorados, a trajetória promovida pela câmera e pelo sujeito nos possibilita observar o documentário, tendo em vista as tensões históricas, sociais e geográficas vividas.

Apontando para um espaço fronteiriço da cultura, um espaço em contato com o não indígena, o documentário aborda as ruínas dos Setes Povos das Missões, de maneira a repensar a influência da história oficial na cultura Mbyá e para indicar a necessidade de se recontar os eventos históricos que marcaram profundamente a forma como os não indígenas observam os guaranis. Tal como as ruínas, os artesanatos vendidos aos turistas, indicam uma fronteira invisível, um espaço de tensão onde se desenvolvem as estratégias encenativas utilizadas pelos indígenas para recontar e recompor a sua própria História.

\section{Aldeias, subjetividades e alteridade}

O documentário se estrutura narrativamente tendo por base três espaços: as aldeias Anhentenguá, Koenju e as ruínas de São Miguel das Missões. Esses espaços são importantes como uma forma de observarmos a maneira como os comentários são apresentados e de como os indígenas constituem um diálogo com os não indígenas. Essa alteridade não indígena é apresentada nos comentários como 
uma referência constante, como na sequência, na aldeia Anhentenguá, em que os indígenas caçam um passarinho, e, após tratarem o animal, se questionam acerca da maneira pelas quais não indígenas possivelmente se indignariam diante da forma como tratam o animal (Fig. 2).
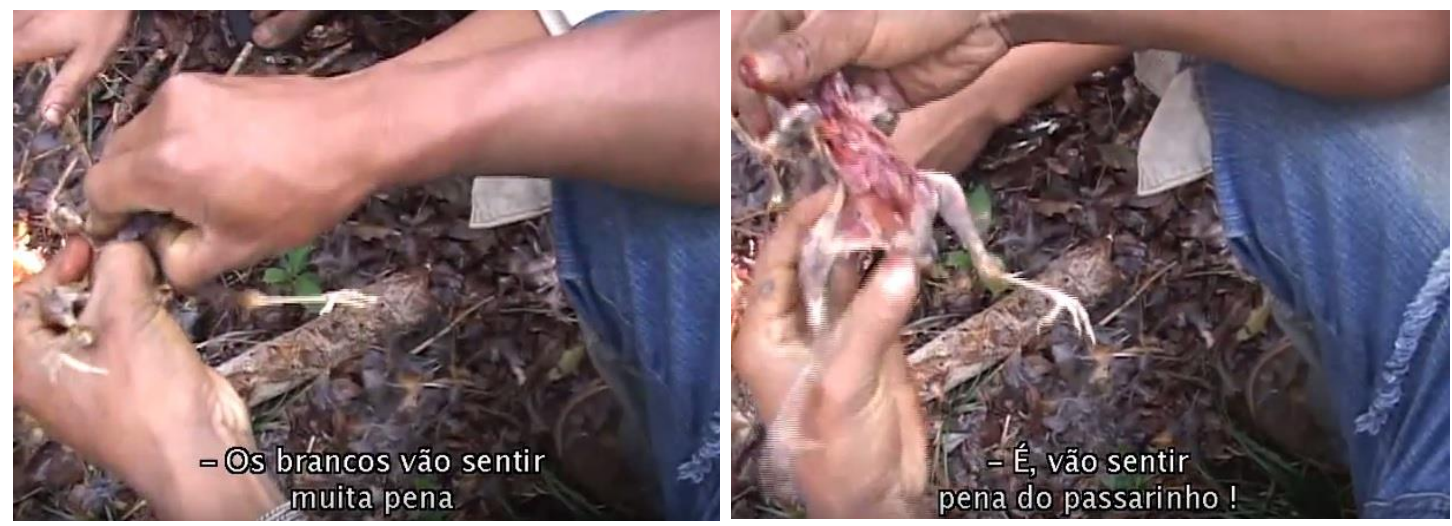

Fig. 2 - Duas aldeias uma caminhada (2008): 8'33"

Ainda nessa primeira aldeia, outro momento importante que destacamos ocorre quando os realizadores se colocam diante da câmera para apresentar a sua proposta de documentário. A sequência se apresenta em um claro modelo encenativo, estratégia narrativa importante para o documentário. Esse recurso de encenação será explorado em outros momentos, sendo fundamental para explicar o caminho proposto pela câmera:

Nem todos os guaranis vão poder ver. A gente tem que mostrar o que é importante, por isso tem que ter personagem. Por exemplo, num filme, você tem que saber onde vai terminar. Pode mostrar a aldeia, a cidade, mas tem que ter uma ideia principal para terminar bem. Isso que a gente não definiu ainda. (DUAS ALDEIAS..., 2008, 11' 30")

As palavras do realizador Ariel Ortega, se o fim é ainda incerto, a necessidade de falar das diferenças entre as aldeias e a cidade é uma estrutura a ser buscada. (Fig. 3). Assim como o realizador que se deixa aparecer se posicionando como personagem, o documentário busca enunciar um discurso frente a esta região fronteiriça: a aldeia e a cidade, o indígena e não indígena.

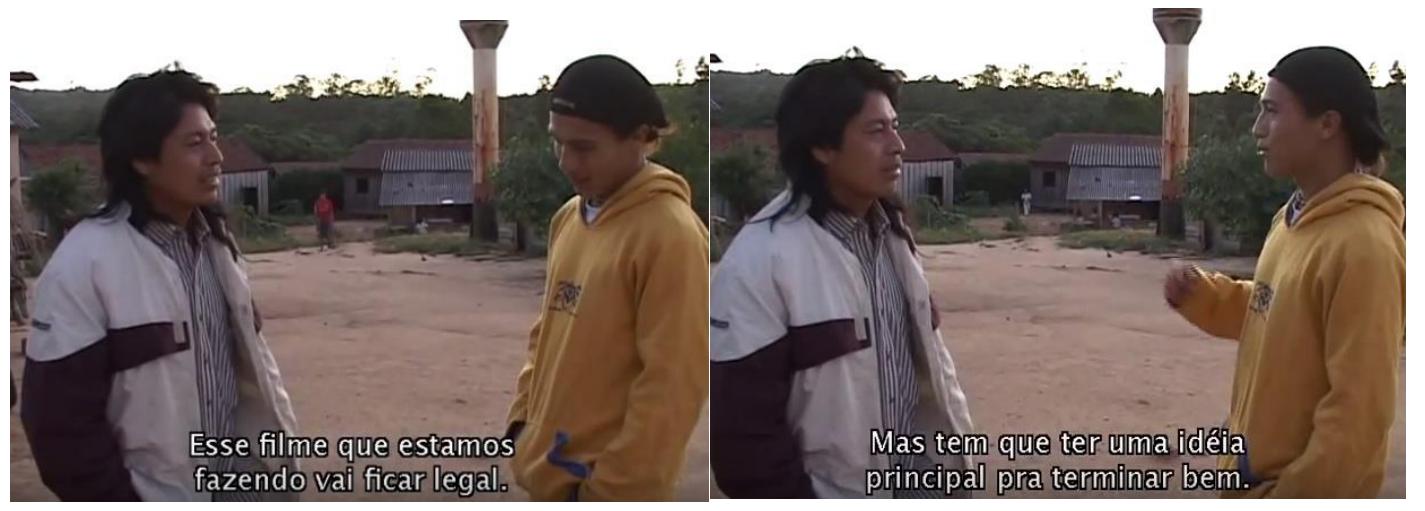

Fig. 3 - Entrevista conduzida por um dos realizadores (de amarelo), e que simula um encontro. Duas aldeias uma caminhada (2008): 11'25"

Ainda nessa sequência, observamos uma sucessão de personagens que ilustra o comentário do realizador, que buscam apresentar o processo de realização do 
documentário. É assim que, por meio de uma montagem paralela, podemos observar as imagens do personagem de Joacito, enquanto a câmera o segue, dando início a um percurso que liga diferentes personagens (Fig. 4): Joacito, as duas crianças, o próprio realizador e seu interlocutor, o cacique Cirilo Morinoco, que havia cruzado aleatoriamente o caminho da câmera. Nessa sequência, temos uma característica bastante comum à realização: a reconstituição do percurso enunciativo por de uma evidenciação do processo de realização.

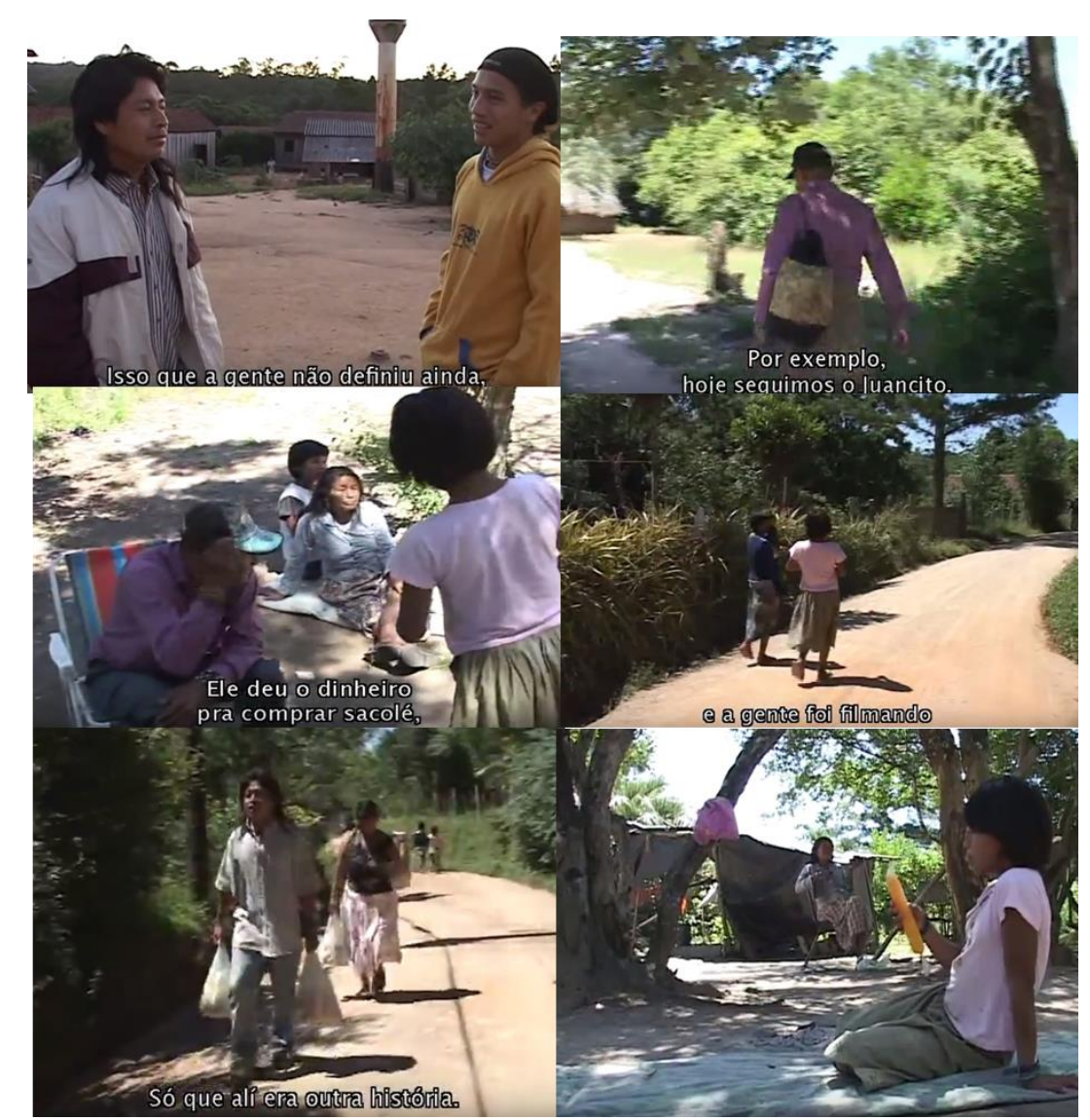

Fig. 4 - Sequência de imagens em montagem paralela, apresentando os diferentes personagens e a busca por uma narrativa. Duas aldeias uma caminhada (2008): 11'30" a 12'12".

É assim que em uma narrativa ainda em busca de um fim, no percurso interrompido da câmera, os sujeitos têm o poder de criar personagens, histórias e uma representação própria para os indígenas. A mobilidade precede a necessidade da constituição de um final tradicional, em prol de uma metáfora baseada na mobilidade e na sua autonomia em constituir um caminho e uma história própria. Da mesma maneira, a busca por um final para o documentário se aproxima da busca por recontar a História oficial: ambas são observadas por perspectivas dos diferentes sujeitos, ao desconstruir as formas estabelecidas de se representar os indígenas, sua cultura e suas tradições.

Na segunda aldeia Koenju, podemos observar de forma mais detida o trabalho dos indígenas na produção do artesanato. Seu trabalho é apresentado em uma estreita relação com seu espaço. As problemáticas sociais e ambientais, expressam-se nos seus afazeres, diante da dificuldade de obtenção de matéria prima que outrora lhe eram acessíveis. As dificuldades decorrentes do isolamento e achatamento da aldeia empurram, cada vez mais, os Mbyá para uma aproximação com os não indígenas, tendo no artesanato um claro ponto de mediação. 
Desse modo, o percurso do artesanato é o fio narrativo que conduz o percurso da câmera pela aldeia. Ao descrever a produção artesanal, a câmera constitui uma cadeia ${ }^{5}$ que se reflete na descrição do espaço e do tempo, tendo por base as atividades envolvidas na confecção dos produtos destinados ao comércio. Nessa cadeia, o trajeto da câmera tem um papel importante de preparar a narrativa para o terceiro momento do documentário: as ruínas dos Setes Povos das Missões. Se outrora esse espaço foi erguido em terras guaranis, sua elevação a patrimônio nacional se apresenta como um monumento à tragédia social e histórica vivida pelos Mbyá.

Nas ruínas dos Setes Povos das Missões não são somente os artesanatos indígenas que despertam o interesse dos visitantes, mas também o modo de vida Mbyá, perceptível nos questionamentos realizados pelos turistas acerca dos seus hábitos tradicionais: tal como o artesanato, uma câmera operada pelos indígenas é um souvenir especial (Fig. 5). É nas palavras de uma das guias de turismo que encontramos um dos típicos discursos acerca dos Guaranis, "sujeitos dóceis e extremamente curiosos para o trabalho escravo" (DUAS ALDEIAS..., 2008, 47” $56 ”)$.

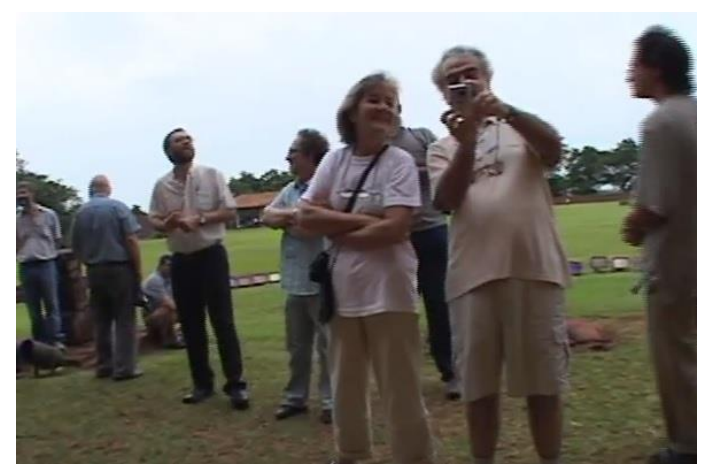

Fig. 5 - Duas aldeias uma caminhada: 47'23"

Mas é diante da câmera de vídeo nas mãos de um Guarani, que a palavra do guia se apresenta como um atestado das formas de domínio da representação constituída pelo não indígena. Mais do que um atestado dos atributos guaranis, a palavra da guia tem o poder de falar mais acerca das formas de dominação, do que uma categorização útil para observarmos a complexidade das subjetividades apresentadas no documentário. Nessa perspectiva, é interessante notar como os Mbyá no documentário passam a ser apresentados de modo distante da doçura e da curiosidade dita pela guia de turismo. Ao contrário, o documentário deixa transparecer que, diante da espetacularização da história oficial, os indígenas caminham por espaços escondidos, onde as luzes da história constroem zonas não iluminadas, espaços de forjamento de uma encenação que seja capaz de mostrar, para os não indígenas, suas próprias contradições.

Caminhando por detrás do palco, os índios passam a apresentar uma visão própria para os acontecimentos históricos que marcaram a história oficial, em especial, as Guerras Guaraníticas. O desfecho para o conflito colonial é apresentado considerando as marcas deixadas na cultura remanescente dos Mbyá. Mais

5 A noção de cadeia é trabalhada aqui em conformidade com o que já foi apresentada por France (1999), como uma "ordem lógico-cenográfica que designa as manifestações do processo filmado relativas à sua articulação interna, existente tanto no espaço quanto no tempo" (p. 406). 
do que um atestado do conflito histórico no sul do país, as ruínas é um monumento ao domínio cultural e territorial imposto, uma ferida inserida nas formas estabelecidas de se contar a história oficial:

\footnotetext{
Os guaranis foram os protagonistas dessa história. Mas agora eles estão ali daquele jeito. A morte deles só tem valor na história. Ainda existimos e os turistas veem os guaranis tentando vender no museu. Essa é a nossa realidade. (DUAS ALDEIAS..., 2008, 51'30")
}

Portanto, em Duas aldeias uma caminhada os sujeitos sãos apresentados, levando em consideração uma autonomia interpretativa acerca da sua cultura e das formas das estratégias de registros documental. Essa autonomia narrativa demonstra o papel ativo que esses sujeitos desempenham diante da câmera. Em outras palavras, a presença da câmera tem um poder especial de instaurar um espaço propício para um posicionamento político e representativo, espaço de diálogo e mediação entre subjetividades, diante de uma mise en scène constituída na relação entre o "sujeito que filma e o sujeito filmado" (COMOLLI, 2006: 60).

\section{Comentários, intersubjetividade e mise en scène}

A forma como a câmera é utilizada na cena é uma característica importante para a compreensão das estratégias utilizadas na realização. Mais do que um meio de registro, a câmera pode ser observada como uma forma de interação entre os diversos sujeitos envolvidos no documentário. A câmera, por sua vez, constitui uma presença, ao possibilitar a encenação dos sujeitos envolvidos no registro. Essa presença tem a importância de instaurar um espaço de encenação, espaço esse marcado pelo intersubjetividade.

Juntamente com os sujeitos sociais, de modo a nos possibilitar identificar a câmera caminha em direção ao encontro, de modo a nos possibilitar identificar duas categorias de mediação: 1) uma estabelecida na relação indígena e indígena, 2) e outra baseada na relação indígena e o não indígena. Essas duas categorias têm influência no desenvolvimento dos comentários realizados pelos indígenas e nas estratégias de registro utilizadas pelos realizadores. Na primeira, podemos situar o uso de entrevistas conduzidas pelos próprios realizadores, quando a câmera ganha um caráter de invisibilidade, de modo a constituir uma opção com foco nos aspectos orais presentes no diálogo. Na segunda, a câmera ganha um contorno de visibilidade, se apresentando como um instrumento fundamental das relações de poderes presentes na relação indígena e não indígena.

\section{Relação indígenas e indígenas}

No documentário, a tradição religiosa é apresentada pelos comentários dos sujeitos filmados, de modo a criar um mosaico de opiniões. Podemos notar que essa ênfase na oralidade desenvolve o que Caixeta de Queiroz (2009: 55) chamou de uma postura purista para as tradições indígenas, perceptível na ideia de uma tradição que necessita se manter intacta, já que muitos comentários, sobretudo dos mais velhos, enfatiza a necessidade de preservação das tradições Mbyá. É aqui que se firma uma importante dualidade: a permanência e a mudança da cultura.

Em sua maioria, esses comentários apontam para os aspectos tradicionais da cultura Mbyá, aspecto esse perceptível não somente no traço linguístico dessas produções - o Mbyá, um dos dialetos da língua Guarani - mas também na ideia 
de mitologias e religião. Como traço presente dessas narrativas, situamos um aspecto bastante comum: o perigo da perda da tradição. Essa possibilidade constitui o fio narrativo que aproxima as diferentes gerações e sujeitos representados no documentário. Se os mais velhos são aqueles sujeitos ligados aos aspectos tradicionais da cultura Mbyá, aos mais jovens compete se reconectar com os aspectos fundantes da cultura (Fig. 6).

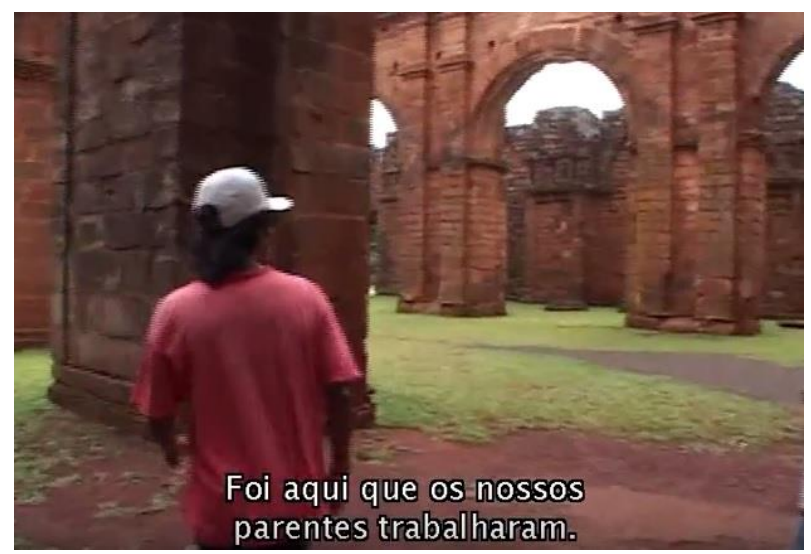

Fig. 6 - comentários que se contrapõe à história oficial. Duas aldeias uma caminhada: 49’16"

Essa perspectiva pode ser observada também no diálogo mediado pelo realizador, Ariel Ortega, em comentários acerca do domínio espacial sofrido pelas aldeias e no achatamento frente ao espaço da cidade. Aqui, além de uma definição do papel enunciativo do realizador, podemos destacar a busca por um reposicionamento do papel prevalente dos Mbyá, tanto na representação dos aspectos históricos quanto da capacidade de apropriação dos recursos técnicos e representativos do documentário.

\section{Indígenas e não indígenas}

Na segunda categoria de mediação, podemos situar os momentos em que o documentário foca no poder dos indígenas em constituir a sua própria narrativa documental. Esse poder se situa diante da capacidade desses de se proporem como enunciadores ao registrarem os não indígenas. Mais do que um personagem, o elemento não indígena é uma alteridade presente nos comentários, se estabelecendo como uma presença particularizada pelos indígenas, tanto por cada um dos indígenas quanto pela coletividade. É assim que o não indígena se torna perceptível nos comentários que aludem à ideia de fronteira, nas referências diretas às cercas como um espaço delimitador da vida na aldeia, bem como diante da perda da mata por parte dos Mbyá.

No documentário podemos encontrar essa relação na referência à mata como um espaço tensionado com o não indígena, bem como nas descrições do espaço da aldeia fincada em um território fronteiriço à cidade e às fazendas. Nessa perspectiva, destacamos, então, alguns momentos importantes. O primeiro é a sequência, já citada anteriormente, e que ocorre na mata utilizada pelos indígenas para a retirada da madeira para a fabricação do artesanato. Nessa sequência, podemos observar os indígenas caçando um passarinho, que após ser morto é consumido pelos indígenas, que o fazem questionando a forma como os nãos indígenas reclamariam ao ver tais cenas em um filme. 
Essa sequência, em especial, nos permite aprofundar nos significados desenvolvidos pelo documentário, nos possibilitando atentar para o sentido metafórico que o passarinho adquire: uma referência aos Mbyá cada vez mais aprisionados. Em outras palavras, Mbyá caçam um passarinho com o intuito de colocá-lo na narrativa, uma forma de atentar para os significados estabelecidos pelos não indígenas. O passarinho tem um significado especial, já que ao passo em que é fabricado e comercializado como artesanato, é consumido também como alimento (Fig. 7).

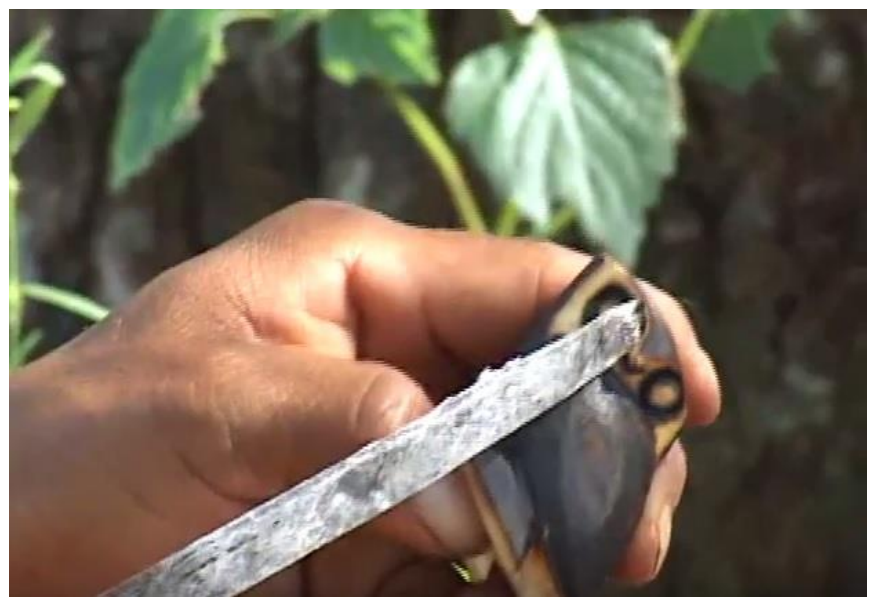

Fig. 7 - Duas Aldeias uma caminhada: 32'27"

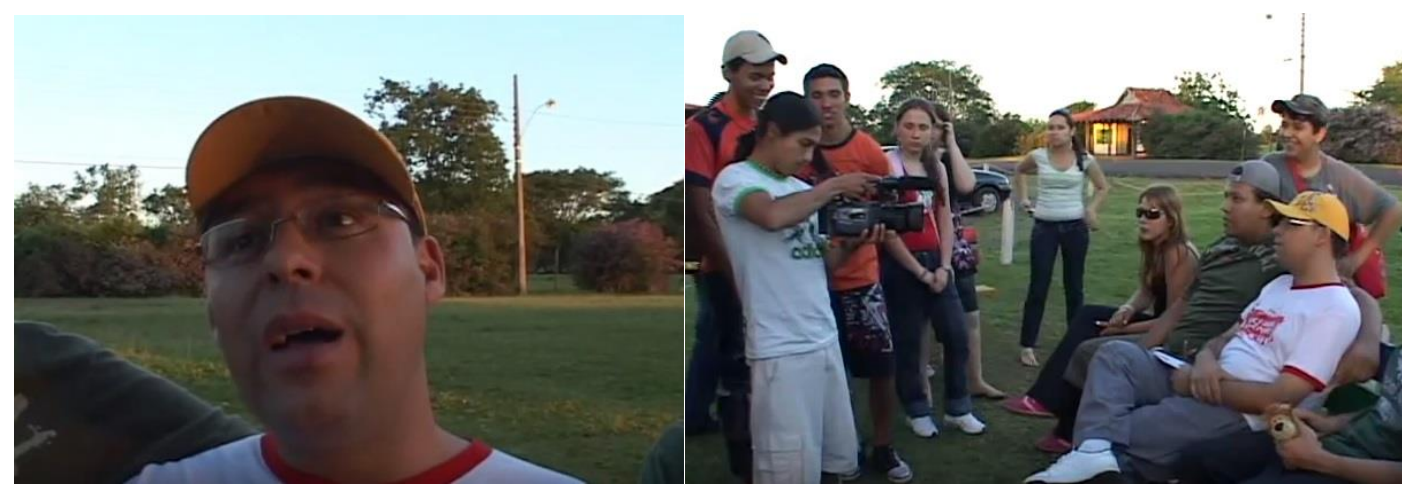

Fig. 8 - Duas aldeias uma caminhada: 54'40"

Outro momento importante ocorre no terceiro espaço da narrativa, a ruína dos Setes Povos das Missões, quando da venda dos produtos indígenas. Aqui, o não indígena aparece pelo olhar dos Mbyá, tendo em vista o discurso que esses enunciam acerca dos indígenas. Os não indígenas são aqueles que carregam uma opinião hegemônica acerca do mundo Guarani. É assim que os Mbyá constroem um discurso de modo a apresentar as contradições acerca da história oficial. Aqui, a câmera na mão dos indígenas parece estabelecer um questionamento acerca das contradições presentes na visão caricatural dos não indígenas (Fig. 8).

\section{Uma caminhada para as fronteiras da cultura Mbyá}

As formas de produção e registro da imagem documental podem ser notadas constantemente no documentário e revelam a própria natureza da imagem proposta por essa realização: a metalinguagem ou, como apontou Ramos (2012, 
p.33), a constituição de uma trajetória que deixe "[...] claro o percurso da enunciação e a medida da distância para essa alteridade”. No diálogo com a câmera, podemos ter acesso, claramente, aos aspectos técnicos envolvidos na produção do documentário. Esse diálogo se apresenta em diversos momentos, quase sempre tendo o indígena como o objeto da câmera. O indígena é aquele que, além das tarefas comuns à vida nas aldeias, é o sujeito em estreito diálogo com a técnica documental, capaz de, por sua própria mão, constituir narrativas acerca de si e do outro.

Diante dessa perspectiva, podemos identificar o que Caixeta de Queiroz (2009: 55) chamou, ao analisar a cinematografia indígena, de uma proposta com foco na mudança cultural presente na relação entre permanência e modificação. A tradição cultural e histórica Mbyá é compreendida por meio das modificações culturais vividas por essas comunidades. A câmera, nesse sentido, constitui um trajeto que abarca tanto uma descrição dos sujeitos indígenas quanto de uma alteridade não indígena, levando em conta as diferentes interpretações desenvolvida pelos sujeitos.

A câmera e o seu sujeito têm um papel importante e ambíguo. Ao passo que podem ser vistos como um dispositivo de mudança, são elementos a reiterar as formas tradicionais da cultura Mbyá. Essa ambiguidade é observada na forma como o documentário descreve os indígenas, desconstruindo formas de espetacularização baseada no estereótipo convencionalmente vinculado ao indígena, tais como os aspectos tradicionais da religião, da sua cultura e da sua terra; mas construindo outras formas de espetacularização como na ênfase em uma experiência individual da cultura tradicional da tradição da própria história Mbyá.

É assim que o tempo cotidiano nos permite observar para as especificidades da produção do registro e dos elementos presentes na cena. A presença da câmera buscaria produzir uma cena marcada pela presentificação dos dispositivos e dos sujeitos envolvidos no processo de feitura. Em outras palavras, a presença da câmera constitui uma temporalidade e uma espacialidade própria dos sujeitos envolvidos na mise en scène.

Em Duas aldeias uma caminhada, a relação entre os sujeitos e a câmera acentua-se a tal ponto que podemos observar sequências em que o sujeito da câmera recebe a alcunha de "câmera". Aqui, apesar de os personagens saberem que a câmera é conduzida por um realizador indígena, ao chamá-lo de câmera, os comentários parecem apontar para a figura do realizador como um sujeito constituído pelas tensões que envolvem o não indígena e o indígena. Como uma metáfora, a câmera aqui pode ser observada como uma espécie de máscara à mercê dos realizadores; uma máscara que apesar de esconder, é também capaz de tornar visíveis os realizadores e os indígenas.

Recebido em 29 de setembro de 2020.

Aceito em 1 de novembro de 2020. 


\section{Referências}

ARAÚJO, Juliano José. Cineastas indígenas, documentário e autoetnografia: um estudo do projeto Vídeo nas Aldeias. Tese (Doutorado em Multimeios). Universidade Estadual de Campinas, 2015.

BARROS, Moacir Francisco Sant'anna de. Caminhada, Canto, Conversação mise-en-scène reversa em três filmes do Coletivo Mbyá-Guarani de Cinema. Tese (Doutorado). Faculdade de Filosofia e Ciências Humanas. Universidade Federal de Minas Gerais, 2014.

BRASIL, André. Bicicletas De Nhanderu: lascas do extracampo. Devires, 9 (1): 98-117, 2012.

CAIXETA QUEIROZ, Rubem. "Relações Interétnicas e Performance Ritual: Ensaio de Antropologia Fílmica sobre os Waiwai do Norte da Amazónia”. In: FREIRE, Marcius; LOURDOU, Philippe (orgs.). Descrever o visível - Cinema Documentário e Antropologia Fílmica. São Paulo: Editora Estação Liberdade, 2009.

CLASTRES, Hélène. Terra sem Mal - o profetismo Tupi-guarani. São Paulo: Brasiliense, 1978.

COMOLLI, Jean Louis. Ver e poder - a inocência perdida. Belo Horizonte: UFMG, 2008.

FRANCE, Claudine. Cinema e Antropologia. Trad. Maria Francisca Marcello. Campinas: UNICAMP, 1998.

LADEIRA, Maria Inês. O caminhar sob a luz. São Paulo: UNESP, 2007.

RAMOS, Fernão Pessoa. A Imagem-Câmera. Campinas: Papirus, 2012.

\section{Filmografia}

MOKOI tekoá petei jeguatá | duas aldeias uma caminhada. Direção de GERMANO BEÑITES, ARIEL DUARTE ORTEGA, JORGE RAMOS MORINICO. Rio Grande do Sul: VÍDEO NAS ALDEIAS, 2008. On line, cor, son. 68'. Disponível em: < http://www.videonasaldeias.org.br/2009/video.php?c=25>. Acesso em fevereiro de 2018. 